\title{
Morphine Manifesto
}

\section{Manifesto pela Morfina}

\author{
Isabel Galriça NETO $\square^{1,2}$
}

Acta Med Port 2016 Mar;29(3):161-163 - http://dx.doi.org/10.20344/amp.7663

Keywords: Analgesics, Opioid; Morphine; Pain.

Palavras-chave: Analgésicos Opióides; Dor; Morfina.

\section{General principles for the use of morphine}

Morphine is a drug used for nearly two centuries. However, it is still surrounded by prejudices and wrongly used in medical practice.

Morphine is a strong opioid, an analgesic agonist of the $\mu$ receptors. The main indications for its use are severe pain, refractory dyspnea and diarrhea - the so-called "3 D's" (in Portuguese Dor, Dispneia and Diarreia). There are different morphine preparations and routes of administration. The oral route is first choice but when caring for frail patients towards the end of life, sometimes an alternative is required; the recommended is the subcutaneous (SC) route. $^{1}$

The correct use of morphine depends on two things: a complete pain evaluation and a progressive dose titration, which means we must evaluate if the patient was previously under opioid treatment (weak or strong). If they were not previously on opioids - 'naïf patient' -, we must begin with oral morphine 5 - $10 \mathrm{mg}$ each 4/6 hours (with special attention to patients who are frail, old or with renal and liver failure). If the patient is not opioid naiif, then we have to consider previous doses, calculating the dose of morphine using consensual conversion ratios for administering higher doses compared to naiif patients - usually, $10 \mathrm{mg}$ orally each $4 / 6$ hours. To raise the dosage safely, we generally calculate an increase of about $30-50 \%$ of the previous dose. It is very important to maintain a regular surveillance of opioid toxicity side effects ${ }^{2}$ Morphine has no maximum dose and most patients are well controlled with doses up to $200 \mathrm{mg} /$ oral/ 24 hours.

When rotating morphine from oral to the SC route, we halve the dose. When rotating to intravenous (IV), we reduce to one third. If the rotation is done in the reverse order, the correction will be to double or triple the dose, respectively. ${ }^{1,2}$ These recommendations should not be ignored; otherwise, there is risk of toxicity or under treatment.

When administering morphine via SC or IV routes, consensus guidelines recommend beginning in bolus, with immediate release preparations, and only after adequate titration and $24 \mathrm{~h}$ total dosage stabilization (including PRN doses) if uncontrolled symptoms persist, progression to continuous infusions is recommended..$^{1,2}$
The correct use of morphine contributes greatly to an impeccable symptom control and to improving the quality of life of patients with an advanced chronic and serious illness. When administered correctly, morphine has few side effects and allows the vast majority of patients to remain alert and able to carry on with their usual day activities, not being necessarily bedbound.

A few years ago morphine was only used in the last days and hours of someone's life, because it was seen as a very dangerous drug, one that shortens life and causes respiratory depression. This belief still exists but our experience in palliative medicine strongly counteracts it. Only when incorrectly used, can morphine cause damage to patients.

\section{Sedation and morphine drip infusions, what for?}

More recently, another use of morphine has slowly emerged in clinical practice: the so-called 'comfort drip infusions of morphine' used in the last days and hours of life, via IV, at $2 \mathrm{cc} /$ hour. A clarification is needed: this use is incorrect and must not be performed, for the following reasons.

Comfort is not an indication for morphine use. As previously stated, morphine has clear indications (the 3 D's $)^{1}$ and if a patient is uncomfortable, namely in the last days and hours of life, one must first evaluate and establish the reason why. The discomfort may be caused by something else other than severe pain, refractory dyspnea or diarrhea, in which case a different type of treatment is required.

The most frequent and discomforting symptoms in the last days and hours of life are delirium with psycho-motor agitation, death rattle and dyspnea. ${ }^{3}$ Having this in mind, morphine use in the terminal phase is not mandatory. Neuroleptics, benzodiazepins and anticholinergics are more frequently used.

Entering the last days and hours of life does not imply the occurrence of pain. ${ }^{2,3}$ Morphine is indicated only if the patient was previously on pain treatment with morphine or if dyspnea re-appears. In the phase of therapeutic titration, we can use a bolus drug regime or, in very specific clinical

1. Palliative Care Unit. Hospital da Luz. Lisbon. Portugal.

2. President of the Palliative Medicine Subspecialty of the Portuguese Medical Association. Lisboa. Portugal.

Autor correspondente: Isabel Galriça Neto. ineto@hospitaldaluz.pt

Recebido: 02 de março de 2016 - Aceite: 09 de março de 2016 | Copyright @ Ordem dos Médicos 2016 
Table 1 - Key points for using morphine

\section{Key points}

- The main indications for using morphine are severe pain, refractory dyspnea and diarrhea

- Morphine has strict rules for administration: initiation at low dosage, progressive titration; preference for oral route; increases not larger than $30-50 \%$ of the previous dose

Morphine has no maximum dose

- Palliative sedation is a medical treatment for refractory symptoms and does not intent to shorten life

Palliative sedation, when correctly performed, does not shorten life

Morphine is not used in palliative sedation

The so-called 'morphine infusions for comfort' are not a correct treatment for the last days and hours of life and should not be used

situations, continuous infusions. According to best practice in end of life care, infusions are mostly administered SC and only occasionally IV, respecting titration rules; they are neither first line measures nor universal in this group of patients. ${ }^{1-3}$

It is false that the majority of the patients treated by palliative care teams die under morphine drip infusions. ${ }^{4}$ It must be emphasized that sedation is not an indication for morphine use,$^{1-5}$ even though there is a sedative effect recognized as a manageable side effect of this drug. This effect is transient, ends after the first $48-72$ hours, and might even be controlled with methylphenidate.

When and if there is indication for progressing to palliative sedation for the treatment of refractory symptoms in the last days of life, first line drugs are midazolan, haloperidol and/ or levomepromazine; second line drugs (more rarely used) are phenobarbital or propofol. ${ }^{1-5}$ Palliative sedation is a treatment that does not shorten life $^{6}$ and does not imply the use of morphine.

A dying patient may be agitated, sometimes groaning. This is a primary form of communication that does not necessarily imply discomfort. It is imperative to exclude the presence of pain and consider terminal agitation; if that is the case, treatment requires the aforementioned sedative drugs..$^{2,3}$

It is very serious that an incorrect medical practice such as the use of morphine drip infusions is being slowly introduced in everyday clinical practice against clinical guidelines and best practice for morphine use towards the end of life. ${ }^{1-6}$ It is even more worrying to see this measure being taken as universal, without considering titration, side effects or toxicity signs. Such malpractice might be considered homicide, involving the physicians that prescribe and those that administrate morphine in this manner.

It is urgent to fix this medical malpractice. All physicians must have the capacity and skills to perform basic palliative interventions - first line measures to reduce suffering in patients with an advanced chronic and serious illness and end of life care interventions (last 12 months of life). ${ }^{7,8}$ The prevalence of these patients in hospital wards is high more than $30 \%$. ${ }^{9,10}$ The correct treatment implies adequate training of the clinicians who care for them. For a large number of people in Portugal, death occurs in hospital ${ }^{10}$ and this is where they spend their last days and hours of life. Not knowing how to use morphine correctly adds suffering to many patients and families, leaving clinicians unprepared for how to deal with the reality of death and dying. ${ }^{7,8}$

This basic intervention in the last days and hours of life does not exempt the need of specialist palliative care teams, who provide consultation and support, particularly in the treatment of the most complex patients, with greater impact if they are involved in the early phase of an advanced and serious illness. ${ }^{7-10}$

To conclude, it is fundamental to keep informing and spreading good end of life practices, so that the crucial value of a gold standard drug like morphine is not compromised (Table 1).

\section{ACKNOWLEDGEMENTS}

The author would like to thank Bárbara Gomes for the english review of the manuscript.

\section{REFERENCES}

1. Twycross R, Wilcock A, Howard P. Palliative Care Formulary (PCF5). $5^{\text {th }}$ ed. Nothingham: Palliativedrugs.com; 2014

2. Sleeman KE, Collis E. Caring for a dying patient in hospital. BMJ 2013;346:f2174.

3. Taylor $\mathrm{P}$, Johnson $\mathrm{M}$. Recognizing dying in terminal illness. $\mathrm{Br} \mathrm{J}$ Hosp

Med. 2011;72:446-50.

4. Cherny; ESMO Guidelines Working Group. ESMO Clinical Practice Guidelines for the management refractory symptoms at the end of life and the use of palliative sedation. Ann Oncol. 2014;25:iii143-52.

5. Cherny N, Radbruch L. The Board of the European Association for 
Palliative Care (EAPC); Recommended framework for the use of sedation in palliative care. Palliat Med. 2009;23:581-93.

6. Maltoni M, Scarpib E, Nannib O. Palliative sedation for intolerable suffering. Curr Opin Oncol. 2014;26:389-94.

7. Kelley AS, Morrison AS. Palliative Care for the Seriously III. N Engl J Med. 2015;373:747-55.

8. Taylor R, Chadwick S. Palliative care in hospital: Why is it so difficult? Palliat Med. 2015;29:770-3.
9. Clark D, Armstrong M, Allan A, Graham F, Carnon A, Isles C. Imminence of death among hospital inpatients: Prevalent cohort study. Palliat Med. 2014;28:474-9.

10. Sarmento VP, Higginson IJ, Ferreira PL, Gomes B. Past trends and projections of hospital deaths to inform the integration of palliative care in one of the most ageing countries in the world. Palliat Med. 2015;30:36373. 